\title{
Factors that Affect the Horizontal Transfer of Transposable Elements
}

\author{
Joana C. Silva ${ }^{1 *}$, Elgion L. Loreto ${ }^{2}$, Jonathan B. Clark ${ }^{3}$ \\ ${ }^{1}$ The Institute for Genomic Research, 9712 Medical Center \\ Drive, Rockville, MD 20850, USA \\ ${ }^{2}$ Departamento de Biologia-CCNE, Universidade Federal \\ de Santa Maria, CEP 97105-900, Santa Maria, RS, Brazil \\ ${ }^{3}$ Department of Zoology, Weber State University, Ogden \\ UT 84408, USA
}

\begin{abstract}
Transposable elements are characterized by their ability to spread within a host genome. Many are also capable of crossing species boundaries to enter new genomes, a process known as horizontal transfer. Focusing mostly on animal transposable elements, we review the occurrence of horizontal transfer and examine the methods used to detect such transfers. We then discuss factors that affect the frequency of horizontal transfer, with emphasis on the mechanism and regulation of transposition. An intriguing feature of horizontal transfer is that its frequency differs among transposable element families. Evidence summarized in this review indicates that this pattern is due to fundamental differences between Class I and Class II elements. There appears to be a gradient in the incidence of horizontal transfer that reflects the presence of DNA intermediates during transposition. Furthermore, horizontal transfer seems to predominate among families for which copy number is controlled predominantly by self-regulatory mechanisms that limit transposition. We contend that these differences play a major role in the observed predominance of horizontal transfer among Class II transposable elements.
\end{abstract}

\section{Introduction}

Transposable elements include a diverse array of DNA sequences that share an inherent property of mobility. In spite of ample evidence for the deleterious effect of mutations caused by the presence and the movement of transposable elements (Lambert et al., 1988; Berg and Howe, 1989; Mackay, 1989; Finnegan, 1992; Nuzhdin, 1999), these sequences are ubiquitous in eukaryotic genomes. One explanation for the persistence of transposable elements (TEs) is that they represent quintessential selfish DNA, using a replicative advantage over non-mobile sequences to increase their copy number

*For correspondence. Email jsilva@tigr.org. within a genome (Doolittle and Sapienza, 1980; Orgel and Crick, 1980). Indeed, in studies that simulate genetic crosses between genomes with and without transposable elements, a TE that is transmitted to $100 \%$ of the resulting progeny can become fixed in the population even when reducing fitness by $50 \%$ (Hickey, 1982). A second explanation for the persistence of TEs is that they in fact benefit the host, providing genetic variability or mediating favorable structural changes in the genome that increase host fitness (McDonald, 1993; McFadden and Knowles, 1997; Kidwell and Lisch, 2000). Several recent studies report the widespread presence of TE-derived sequences in host genes and regulatory regions (Makalowski, 2000; Nekrutenko and Li, 2001; Jordan et al., 2003; Silva et al., 2003). These two hypotheses are not mutually exclusive and both may play roles in the evolution of transposable elements.

In addition to their propensity for intragenomic spread, there is substantial evidence to suggest that TEs can also cross species boundaries to enter new genomes, a process known as horizontal (or lateral) transfer. Although more common for some TEs than others (see below), horizontal transfer has been reported for virtually all types of TEs, including some eukaryotic introns. It is this property for horizontal transfer that may make transposable elements the most versatile selfish DNA. Here, focusing mostly on animal TEs, we review the occurrence of horizontal transfer, examine the methods used to detect such transfers, and discuss properties of both TE and host that make horizontal transfer possible.

\section{Classification and History}

Transposable elements can be divided into two broad classes on the basis of their transposition mechanism and sequence organization (Finnegan, 1989; Capy, 1998). Class I elements, generally referred to as retroelements, move by reverse transcription of an RNA intermediate and include the retrotransposons, group II mitochondrial introns and retroviruses. Like in retroviruses, the reverse transcriptase of Class I TEs is usually encoded by the element itself. The two major subclasses of Class I elements can be distinguished by the presence or the absence of long terminal repeats (LTRs), which flank the body of the element. Among the best-known LTRcontaining retrotransposons (or LTR retrotransposons) are the Ty1-copia and Ty3-gypsy superfamilies and the retroviruses. Retrotransposons that lack LTRs (or non-LTR retrotransposons) include, among others, the long interspersed elements (LINEs) and short interspersed elements (SINEs) of vertebrate genomes and the I family of Drosophila. Class II elements, or transposons, move predominantly via a DNA-mediated mechanism of excision and insertion (e.g., Kaufman and Rio 1992), although a few rolling-circle transposons are also known (Mendiola et 
al., 1994; Kapitonov and Jurka, 2001). Many Class II elements encode a transposase and possess relatively short inverted terminal repeats, both of which are necessary for their mobility. Although many Class II elements share some sequence and structural homology, it seems unlikely that all Class II elements share a common origin. Among the major groups of Class II elements are the mariner-Tc1 superfamily, which is widely distributed among animals, the $P$ element family of drosophilids and other flies, the piggyBac elements from butterflies, the $h A T$ superfamily, which includes hobo, Ac, and Tam3 and occurs in plants and animals, and some bacterial insertion sequences.

The evolutionary history of TEs is considerably more complex than suggested by the classification scheme described above, and is currently the subject of much research. Non-LTR elements seem to be an ancient, monophyletic lineage that predates the diversification of eukaryotes (Malik et al., 1999) and may have originated from group II introns (Zimmerly et al., 1995; Dai and Zimmerly, 2002). The LTR retrotransposons seem to be much younger, and may have originated from the fusion of a non-LTR retrotransposon with a Class II TE, the former providing the machinery for reverse transcription and the latter the integrase activity (Capy et al., 1996; Malik and Eickbush, 2001). Vertebrate retroviruses, in turn, form a clade within the LTR retrotransposons, and are closely related to the retrotransposon superfamily Ty3-gypsy (Xiong and Eickbush, 1990; Pélisson et al., 1997; Malik and Eickbush, 2001). The common ancestry of the integrase of LTR retrotransposons and the transposase of some Class II elements establishes an evolutionary link between the two Classes (Capy et al., 1996). The emerging picture is one of a modular evolution of TEs whereby new TE families are formed when an existing TE acquires structural features perfected by another (Ivics et al., 1996; Lerat et al., 1999; Malik and Eickbush, 2001). In spite of being a characteristic feature of these TEs, the transposases of different Class II families apparently have independent origins (Capy et al., 1996).

\section{Detecting Horizontal Transfer}

When TEs are transmitted vertically, their phylogenetic history is expected to retrace, at least in broad terms, that of their hosts. Such seems to be the case, for example, for the non-LTR elements $R 1$ and $R 2$ among species of the melanogaster species subgroup of the genus Drosophila (Eickbush and Eickbush, 1995): individual copies isolated from each of the species form monophyletic clades and the relationships among these clades reflect those that connect their host species. It is departures from this expectation, the phylogeny of the TE given that of the host, that allow us to infer that horizontal transfer has taken place.

Three types of distortion of the expected TE phylogeny are commonly used to detect horizontal transfer of TEs. The first, which seems to offer the strongest evidence, relies on the detection of elements with a high degree of sequence similarity in divergent taxa. In this case the branch lengths of the TE phylogeny are much shorter than expected, since the divergence between TE sequences is much smaller than the divergence between non-mobile nuclear genes of their respective host species. This method has been used to identify multiple cases of horizontal transfer for mariner (Maruyama and Hartl, 1991; Robertson and Lampe, 1995) and for the $P$ element (Daniels et al., 1990b; Loreto et al., 2001). Inference of horizontal transfer that rely on this type of distortion may be complicated by analyses that fail to consider variable rates of sequence change that have been shown for some TE lineages (Malik et al., 1999).

A second method, also providing strong evidence, is the detection of topological differences between the phylogenies of TE and host species. Major disparities between the tree topology of TE and host have been detected in some instances, such as for $P$ elements (Clark et al., 1994; Clark and Kidwell, 1997; Haring et al., 2000), for mariner elements (Robertson and MacLeod, 1993) and for gypsy (Terzian et al., 2000). There are, nevertheless, potential problems with relying exclusively on this measure to infer horizontal transfer. The topology of the TE phylogeny may be obscured by the presence of multiple TE lineages within the genome of some species. For example, there may be as many as nine distinct mariner lineages within the genomes of some species, each in essence representing paralogous sequences with distinct evolutionary histories (Lampe et al., 2001). Because most phylogenetic studies of TEs are based on characterization of PCR-amplified products, it is often not possible to determine if phylogenetic incongruence is a result of comparison of paralogous sequences or truly reflects horizontal transfer.

A third method of inferring horizontal transfer is the so-called "patchy" distribution of a TE family among closely related taxa. This term refers to the presence of a TE in one lineage and its absence in a sister lineage, resulting in the absence of one or more branches in the TE phylogeny. This inference relies on the assumption that the lineage possessing the TE has acquired it through a horizontal transfer event that did not involve its sister lineage. By itself, this kind of evidence provides only weak support for horizontal transfer since it is possible for a TE to be lost from the genome through population dynamics or ecological forces that are difficult to reconstruct (Kaplan et al., 1985; Lohe et al., 1995). This situation is analogous to the assortment of an ancestral polymorphism that may lead to the loss of a particular allele from a gene pool.

For those transposable elements for which the case is the strongest, horizontal transfer is confirmed by all three methods; this is the case, for example, of numerous instances of horizontal transfer involving the Class II TEs $P$ and mariner. The situation for horizontal transfer of some other transposable elements is not as strong as for those two families, often resting on one or two methods of detecting the transfer. While horizontal transfer remains a viable hypothesis, careful analysis may reveal alternative explanations for inconsistencies in the phylogeny of a transposable element relative to that of the hosts. For example, re-analysis of the data for several non-LTR retrotransposable elements led to the conclusion that the evidence for horizontal transfer, which had been inferred strictly on the basis of phylogenetic incongruence, was in fact not as strong as originally reported (Malik et al., 1999). 
For reviews of horizontal transfer and alternative explanations, see Cummings (1994) and Capy et al. (1994).

\section{Horizontal Transfer Is Widespread}

Within the past decade, there have been numerous reports of horizontal transfer involving transposable elements (Kidwell, 1993; Clark et al., 2002; Robertson et al., 2002). These and more recent examples of horizontal transfer are summarized in Table 1. Although not intended to be exhaustive, the listing is informative in three respects. First, it shows that horizontal transfer has been documented for all types of TEs. Second, it illustrates that such events have been reported with increasing frequency. And finally, it reflects the skew that is observed in the literature for a preponderance of cases of horizontal transfer that involve Class II TEs.

\section{Lateral movers par excellence: the $\mathrm{P}$ and the mariner families}

To date, the strongest cases of horizontal transfer involve the Class II TEs mariner and the Pelement. In addition, it seems that horizontal transfer within these two families occurs with relatively high frequency in an evolutionary timescale, and this mode of transmission appears to be an integral component of the life cycle of both mariner and $P$ elements (Kidwell, 1994; Lohe et al., 1995; Pinsker et al., 2001).

The $P$ element family was discovered in $D$. melanogaster where it is responsible for the phenomenon of hybrid dysgenesis (Kidwell et al., 1977). The Pelements from this species, termed canonical, have a complete structure and are capable of transposition. Subsequent studies have revealed canonical $P$ elements in other species of Drosophila as well (Clark et al., 1995). Together, these canonical $P$ elements comprise a subfamily in which individual elements differ by less than $10 \%$ in nucleotide sequence. The $P$ family contains several other subfamilies, a few of which, namely the O-, M- and T-type, have been well characterized (Pinsker et al., 2001). The canonical $P$ element of $D$. melanogaster and the consensus sequence of canonical $P$ elements from $D$. willistoni differ by less than $0.1 \%$ at the nucleotide level, in spite of the fact that these two species diverged from one another approximately 40 million years ago (Daniels et al., 1990b). Furthermore, the phylogeny of canonical $P$ elements is clearly incongruent with that of the species in which they are found (Clark et al., 1994), and canonical $P$ elements are completely absent from the genomes of those flies most closely related to $D$. melanogaster (Clark et al., 1998). All these pieces of evidence contribute to make this one of the strongest cases of horizontal transfer (Figure 1). A second example in which horizontal transfer of the canonical $P$ element has been supported by all three detection methods was reported recently involving a member of the willistoni species group (possibly $D$. nebulosa) and a distantly related species, $D$. mediopunctata (Loreto et al., 2001; Figure 1). In addition, careful analysis of the molecular sequence evolution of the canonical $P$ element isolated from several species of the willistoni and saltans species groups has revealed

\begin{tabular}{|c|c|}
\hline TE family & Reference \\
\hline \multicolumn{2}{|c|}{ Class I: non-LTR retrotransposons } \\
\hline LINE / jockey & Mizrokhi and Mazo, 1990 \\
\hline LINE / Bov-B & Kordis and Gubensek, 1995 \\
\hline SINE / Smal-cor & Hamada et al., 1997 \\
\hline LINE / Rex1 & Volff et al., 2000 \\
\hline LINE / Bov-B & Zupunski et al., 2001 \\
\hline \multicolumn{2}{|c|}{ Class I: LTR retrotransposons } \\
\hline Ty1-copia / Ta1-Ta10 & Konieczny et al., 1991 \\
\hline Ty1-copia / copia & Jordan et al., 1999 \\
\hline Tyз-gypsy / SURL & Gonzalez and Lessios, 1999 \\
\hline Tyз-gypsy / gypsy & Terzian et al., 2000 \\
\hline Ty3-gypsy / gypsy & Vazquez-Manrique et al., 2000 \\
\hline \multicolumn{2}{|l|}{ Class II } \\
\hline hTA / hobo & Daniels et al., 1990a, Simmons, 1992 \\
\hline hTA / hobo-Ac-Tam3 & Calvi et al., 1991 \\
\hline$h T A / T o l 2$ & Koga et al., 2000 \\
\hline mariner-Tc1 / mariner & Maruyama and Hartl, 1991 \\
\hline mariner-Tc1 / mariner & Lidholm et al., 1991 \\
\hline mariner-Tc1 / mariner & Lohe et al., 1995 \\
\hline mariner-Tc1 / mariner & Robertson and Lampe, 1995 \\
\hline mariner-Tc1 / mariner & Smit and Riggs, 1996 \\
\hline mariner-Tc1 / Tc1 & Lam et al., 1996 \\
\hline mariner-Tc1 / Tc1 & Ivics et al., 1997 \\
\hline mariner-Tc1 / mariner & Brunet et al., 1999 \\
\hline mariner-Tc1 / Tc1 & Arca and Savakis, 2000 \\
\hline mariner-Tc1 / mariner & Yoshiyama et al., 2001 \\
\hline mariner-Tc1 / mariner & Gomulski et al., 2001 \\
\hline mariner-Tc1 / mariner & Robertson et al., 2002 \\
\hline mariner-Tc1 / ItmD37E & H. Shao and Z. Tu (unpublished results) \\
\hline$P$, canonical & Daniels et al., 1990b \\
\hline$P$, M-type & Hagemann et al., 1992 \\
\hline$P$, canonical & Clark et al., 1994 \\
\hline$P$, O-type & Hagemann et al., 1996 \\
\hline$P$, canonical & Clark and Kidwell, 1997 \\
\hline$P, \mathrm{M}$ - and O-types & Haring et al., 2000 \\
\hline$P$, canonical & Silva and Kidwell, 2000 \\
\hline$P$, canonical & Loreto et al., 2001 \\
\hline
\end{tabular}

numerous additional instances of horizontal transfer that occurred so recently as to escape detection by phylogenetic methods (Silva and Kidwell, 2000; Figure 1).

Strong evidence, corroborated by all three inference methods, is also available for horizontal transfer of noncanonical $P$ elements (Figure 1). For example, elements of both the $\mathrm{O}$ - and M-type subfamilies have been transferred independently between the genus Drosophila, the genus Scaptomyza and the genus Lordiphosa, as shown by the high similarity among elements in those taxa, by the discordance between TE and host phylogeny and the patchy distribution of similar Pelements among related taxa (Simonelig and Anxolabéhère, 1991; Hagemann et al., 1994; Hagemann et al., 1996; Haring et al., 2000).

Like the $P$ element family, the mariner family also consists of multiple subfamilies (Robertson and MacLeod, 1993; Robertson et al., 2002). However, unlike Pelements, which are prevalent mainly among drosophilid flies, the mariner elements are present in multiple animal phyla, among which are cnidarians, platyhelminthes, arthropods (including several insect orders) and vertebrates 

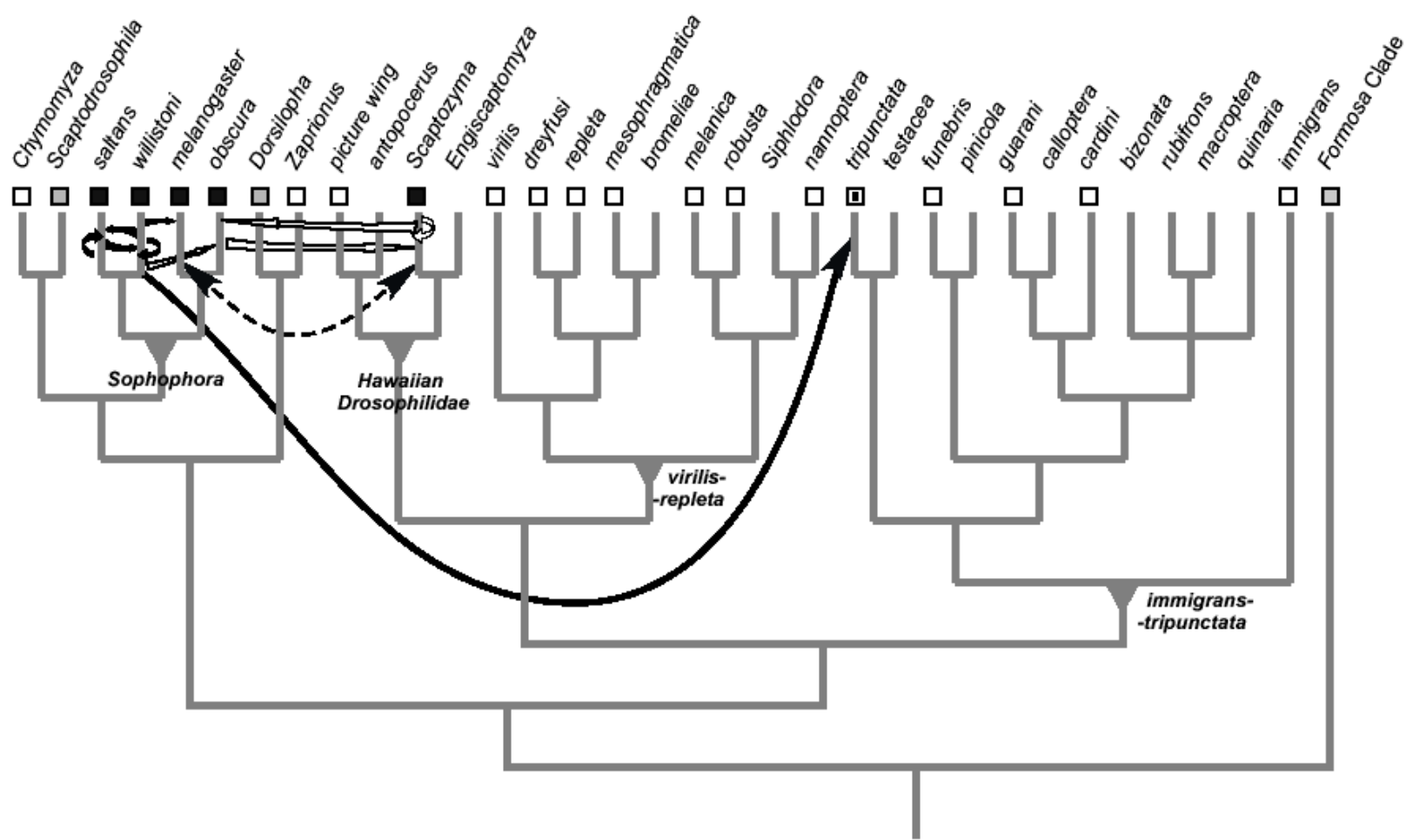

Figure 1. Distribution and horizontal transfer of $P$ elements within the dipteran family Drosophilidae. Each lineage shown represents a species group that has been surveyed by either Southern blot hybridization or PCR for the presence of $P$ elements (Daniels et al. 1990b; Harring et al. 2000). Dark squares denote a strong $P$ element signal, gray squares denote weaker signals, and open squares denote no signal. Detectable $P$ elements are absent from all species surveyed from the tripunctata group with the exception of $D$. mediopunctata (dotted square). Horizontal transfer events are identified with arrows using the following key: filled arrows, canonical $P$ elements; open arrows, M-type $P$ elements; dashed arrows, O-type $P$ elements. Host phylogeny is based on Remsen and O'Grady (2002).

(Robertson and MacLeod, 1993; Auge-Gouillou et al., 1995; Garcia-Fernandez et al., 1995; Oosumi et al., 1995; Robertson, 1997), and have also been detected in plants (Jarvik and Lark, 1998) and fungi (Langin et al., 1995). This widespread distribution has been attained, to a certain extent, by horizontal transmission, as suggested by the very high sequence similarity between elements sampled from distantly related hosts, the incongruence between TE and host phylogeny and the patchy distribution of each mariner subfamily among closely related taxa (Maruyama and Hartl, 1991; Robertson and MacLeod, 1993; Brunet et al., 1994; Lohe et al., 1995; Robertson and Lampe, 1995; Smit and Riggs, 1996; Robertson, 1997; Robertson et al., 2002).

\section{Other Cases of Horizontal Transfer}

Extensive data, such as that which exists for mariner and for the $P$ element, are currently unavailable for other Class II transposable elements. However, recent studies suggest that horizontal transfer may be quite common among most members of this Class. For example, a recently-discovered family, known as ITmD37E, has been found in mosquitoes of the genera Aedes, Anopheles, Armigeres and Toxorhynchites (Shao and Tu, 2001). In spite of its recent discovery, cases of horizontal transfer involving elements of this family have already been detected $(\mathrm{H}$. Shao and $\mathrm{Z}$. Tu, unpublished results).
The strongest case of horizontal transfer among Class I elements involves the LTR retroelement copia of Drosophila (Jordan et al., 1999). In this study, copia elements from $D$. melanogaster and $D$. willistoni were found to be more than $99 \%$ identical in sequence, a much higher level of sequence conservation than observed for nonmobile nuclear genes. It is interesting that these same two species were also involved in the first reported case of horizontal transfer of the canonical $P$ element, which was described above. In the $P$ element case, the transfer was undoubtedly from $D$. willistoni to $D$. melanogaster, whereas the copia transfer appears to have been in the reverse direction. It is tempting to speculate that these two species share an ecological connection that facilitates the process of horizontal transfer. Recent studies also provide evidence for the horizontal transfer of gypsy, another LTR retrotransposable element originally isolated from Drosophila (Terzian et al., 2000; Vazquez-Manrique et al., 2000) and for the SURL elements of echinoderms (Gonzalez and Lessios, 1999).

The evolution of non-LTR retroelements appears to be governed largely by vertical transmission (Malik et al., 1999). However, recent reports suggest that occasional horizontal transfer of some elements may occur. These include the Smal-cor elements of whitefish (Hamada et al., 1997) and the Bov-B elements, which are found in ruminants and some squamates (Zupunski et al., 2001). 
Currently, it is not known how widespread the phenomenon of horizontal transfer is among the Class I TEs. While horizontal transfer remains a viable hypothesis, careful analysis may reveal alternative explanations for inconsistencies in the distribution or phylogeny of a transposable element. Two recent investigations of retrotransposable element evolution in plants discuss the difficulties associated with attempting to distinguish between horizontal transfer and alternative explanations, especially when the transfer events are postulated to have occurred in the distant past (Frissen et al., 2001; StuartRogers and Flavell, 2001).

\section{Initiating Horizontal Transfer: Vectors And Opportunities}

In order for a TE to be exchanged between two cells, a vector of some sort is needed to mediate the physical transfer of DNA from a donor to the recipient's germline. A vector of this nature belongs necessarily to a limited set. Potential vectors need to have access to the intracellular environment, or to be otherwise capable of accessing the cells without destroying them. In addition, horizontal transfer requires not only that the distributions of donor and recipient overlap in a geographic sense, but it is probably facilitated by ecological and temporal overlap as well.

\section{Vectors}

Although numerous studies provide support for the hypothesis of horizontal transfer, with a few exceptions, such as that of the canonical Pelement (Houck et al., 1991), they do not present a satisfying proposal for how transfer may have occurred. Suitable vectors for horizontal transfer in natural populations include viruses (Miller and Miller, 1982; Fraser et al., 1985; Jehle et al., 1995), parasitoid wasps (Yoshiyama et al., 2001) and parasitic mites (Houck et al. 1991). Recently, intracellular parasites have also been placed in the list of plausible vectors. Heath and collaborators (1999) had shown that an intracellular parasite of the genus Wolbachia could be transferred between host species. Now, transfer of nuclear material between Wolbachia and an insect host has also been documented, although the mechanism for such transfer remains elusive (Kondo et al., 2002). These promising hypotheses notwithstanding, it is worth noting that to date none of these vectors has been observed to mediate horizontal transfer of a TE between two hosts, either in natural or in laboratory populations.

An interesting situation exists with the Class I element gypsy. This TE can act as an endogenous retrovirus, since it encodes an envelope protein and possesses infectious properties (Kim et al., 1994). Gypsy can produce virus-like particles (Lécher et al., 1997) and it has been shown in experimental conditions that gypsy can be horizontally transmitted between Drosophila species (Mejlumian et al., 2002). Thus, in principle, horizontal transfer of gypsy would not require a vector.

\section{Overlap Between Donor and Recipient Hosts}

A fascinating example of horizontal transfer of an element of the mariner family between a parasitoid wasp and its lepidopteran host provides a good example of the ecological overlap between donor and recipient that must accompany horizontal transfer (Yoshiyama et al., 2001). In this case, the parasitoid possesses a mariner element with $97 \%$ sequence identity to that of its moth host, whereas related wasps species do not possess mariner at all. However, in spite of this close physical association between parasitoid and host, a vector, such as a virus, may still be necessary to mediate the actual transfer of TE DNA between cells.

The transfer of canonical $P$ elements between $D$. willistoni and $D$. melanogaster illustrates the geographical overlap that is a prerequisite for horizontal transfer between donor and recipient. D. melanogaster is an Old World species whose distribution has only recently expanded to the New World, probably as a result of human activity (Kidwell, 1983; Engels, 1992). Thus, the horizontal transfer of the canonical $P$ element was only possible once the distributions of $D$. melanogaster and $D$. willistoni partially overlapped, an event that occurred relatively recently (Daniels et al., 1990b).

Biémont and colleagues (1999) extend the importance of the overlap between donor and recipient when they suggest that the expansion of a species' range may be concomitant with the genomic invasion by TEs. This invasion can be explained both by the horizontal transfer of alien TEs from new species with which the invading species comes into contact, or by the activation of longtime resident $\mathrm{TEs}$, leading to an increase in genomic copy number. Thus, to a certain extent, a newly acquired overlap of donor and recipient may lead to horizontal transfer by providing the opportunity for such an exchange. This hypothesis has been invoked to explain the recent invasion of $D$. melanogaster by $P, I$ and hobo elements, and of $D$. simulans by the retrotransposon 412 (Vieira et al., 1999).

A similar coincidence of expansion of host range and invasion of TEs by horizontal transfer is apparently occurring with the drosophilid species Zaprionus indianus. Flies of the genus Zaprionus are of afrotropical origin, and are closely related to the genus Drosophila (Remsen and O'Grady, 2002; Figure 1). Z. indianus is in the process of expanding its range, having recently invaded South America, and is rapidly spreading throughout Brazil and neighboring countries (Vilela, 1999). In addition, the ecological niche of $Z$. indianus is very similar to that of $D$. simulans and these species are now often found together in Brazil (E. L., unpublished results). Concomitant with this range expansion, horizontal transfer of gypsy between $D$. simulans and $Z$. indianus has been described by Herédia (2002), based on incongruence between TE and host phylogenies. Comparison of sequence divergence of a nonmobile nuclear gene (superoxide dismutase, Sod) and the gypsy sequences (Table 2) in these species provides additional corroboration of the hypothesis of horizontal transfer. The divergence of the TE sequences is considerably less than that of a host gene supposedly evolving under purifying selection. In order to further explore this possibility, PCR was used to screen 35 Neotropical 
species (14 from the subgenus Sophophora, 19 from the subgenus Drosophila, and one each from the subgenus Dorsilopha and Zaprionus indianus) for the presence of elements from the 297/tom group of retrotransposons. A fragment with the expected size was amplified only from species of the melanogaster group and from $Z$. indianus (E. L., unpublished results). Once again the divergence between the TE sequences is lower than that of the host gene, suggesting a possible horizontal transfer (Table 2). A careful examination of alternative possibilities is currently underway. Finally, Brunet and collaborators (1999) have detected the presence of mariner elements in Zaprionus indianus. These elements are very closely related to that of $D$. simulans (Table 2). Whether the introduction of all these TE families into the $Z$. indianus genome is indeed recent, and results from the expansion of the species range remains to be shown, but the possibility is fascinating and certainly warrants further investigation.

\section{Factors Affecting the Frequency of Horizontal Transfer}

A horizontal transfer event, defined as the successful invasion of a new species by a TE, can be divided into two phases: the transfer of DNA between donor and recipient and a subsequent increase in TE frequency (Kidwell, 1992). The first phase requires the physical transfer of the TE from one organism to another, the stable integration into the recipient's germline and the expression of the TE's coding sequences. Once a stable transfer is achieved, the element must increase in copy number within the cell and then spread throughout the population in order for horizontal transfer to succeed.

Any one of these events seems unlikely, and yet horizontal transfer requires that they occur together, in a coordinated manner. Because the presence and mobility of a transposable element may be deleterious to the host (for a review see Nuzhdin, 1999), this spread will be counteracted by selection and by host- and TE-encoded mechanisms that repress transposition. Therefore, not only will an inherent predisposition of a TE to perform any of the required steps increase its probability of a successful transfer but, ultimately, the structure and transposition mechanism of a TEs are actively molded by the coevolution between host and TE.

\section{Stable Integration into a New Genome}

The physical transfer of nuclear DNA from one species to another must occur in such a manner that the recipient cell is able to take up the donor DNA. Once this occurs, the DNA must enter the nucleus of a germline cell, integrate into a chromosome and be expressed. This process is best understood for the $P$ element, which for twenty years has been used routinely to transform Drosophila (Rubin and Spradling, 1982). In this case, a $P$ element construct, carrying the terminal inverted repeats, is microinjected into the syncytial blastoderm of early embryos, where the $P$ elements subsequently transpose into the recipient's genome. This requires a supply of transposase, which is produced from transcription of a transposase gene that is co-injected with the $P$ element construct. Only some of these insertions will occur in nuclei of those cells that will
Table 2. Divergence (substitutions per nucleotide) of a host marker (Sod) and of TEs between $Z$. indianus and two Drosophila species ${ }^{1}$.

\begin{tabular}{ccc}
\hline & D. melanogaster & D. simulans \\
\hline $\begin{array}{c}\text { D. simulans } \\
\text { Sod }\end{array}$ & & \\
gypsy $^{2}$ & 0.03 & \\
& 0.12 & \\
Z. indianus & & \\
Sod $^{2}$ & & \\
gypsy $^{2}$ & 0.32 & 0.33 \\
17.6/tom $^{3}$ & 0.11 & 0.07 \\
mariner $^{4}$ & & 0.17 \\
\hline
\end{tabular}

${ }^{1}$ Divergence estimated according to Kimura's 2-parameter model (Kimura, 1980).

2 Herédia (2002).

${ }^{3} \mathrm{E}$. Loreto, unpublished results.

${ }^{4}$ Genbank accession numbers for $D$. simulans (AF037052) and Z. indianus (AF034700) mariner elements.

ultimately form germline tissue, potentially producing a stable fly lineage that is genetically transformed. In the laboratory, a strong promoter is used to provide the necessary level of transposase that is needed for mobility. However, in nature the integration and proper expression of a TE would seem to be a daunting impediment to successful horizontal transfer.

Some of the complex features required for horizontal transfer are integral characteristics of the life cycle of some TE families, and reflect selection on TEs for effective transposition. For example, the transposase of class II elements belonging to the mariner-Tc1 superfamily have been found to contain a nuclear localization signal, which explains the migration of these enzymes to the nucleus (either upon translation or after co-transfer with its TE), where they facilitate TE transposition (Ivics et al., 1996). Since Class II TEs transpose predominantly via DNAmediated processes (Kaufman and Rio, 1992; see Hartl et al., 1997 for a review of transposition in mariner-Tc1 elements), extra-chromosomal DNA copies of the element are a necessary feature of their transposition mechanism. Class I elements, on the other hand, depend on extrachromosomal copies of the element in the form of RNA intermediates, which are necessarily not as stable as DNA. As is the case for the transposase of Class II elements, the enzymes encoded by Class I elements need to be produced at levels high enough to ensure transposition.

Differences in the transposition mechanism of LTR and non-LTR Class I elements provide useful insights into varying rates of horizontal transfer among TE families. During the transposition of LTR retroelements, a DNA intermediate is produced, which can insert into the genome in a manner analogous to Class II elements (Luan et al., 1993, and references therein). However, for non-LTR transposable elements, an RNA intermediate is reversetranscribed directly into a chromosomal target site (Luan et al., 1993). Malik and collaborators (1999) suggested that this difference might be sufficient to explain the rarity of non-LTR elements' horizontal transfer. The transposition mechanism used by non-LTR TEs does not preclude the 
possibility of horizontal transfer using a virus as vector, but reverse transcription probably has to occur directly into the viral DNA, an event that might be exceedingly rare.

Thus, there appears to be a gradient of horizontal transfer that reflects the presence of DNA intermediates during the transposition events. Horizontal transfer seems much more common for Class II elements for which DNA intermediates are a persistent feature of the transposition process. Horizontal transfer seems to be less common for Class I LTR retroelements, which produce a DNA intermediate only after reverse transcription of an RNA copy, and horizontal transfer is least common for the Class I non-LTR elements, for which no DNA intermediate is produced.

\section{Spread Within the New Host}

After stable integration and expression, there must be an increase in copy number in order for the TE to spread reliably throughout the population. The increase in copy number within the cell results in a decrease in the probability of a gamete being formed that carries no copies of the element. If fact, if all copies segregate independently, that probability decreases exponentially as $(1 / 2)^{n}$, where $n$ is the total number of copies per genome. This scenario is simplistic, as TE spread may be influenced by other factors, including biases in TE insertion sites. For example, several TEs have been shown to transpose preferentially to sites close to the parental copy (Engels, 1989), meaning that these copies would not segregate independently. However, this model clearly exemplifies the powerful effect of copy number increase on TE transmission; if an individual carries in its genome ten TE copies that segregate independently of each other, the probability of it generating a gamete with no TEs is less than one in a thousand.

Several studies have addressed the subject of TE spread, both by quantifying the number of TE copies per genome and by estimating the rate of spread of TEs in populations. Pelements have been shown to spread rapidly when first introduced into naive populations (those that lacks the TE in question) in the laboratory (Kidwell et al., 1988; Good et al., 1989). These results mimic the spread of $P$ elements throughout natural populations of $D$. melanogaster within the past 50 to 100 years (Anxolabéhère et al., 1988), with most flies examined recently carrying up to $60 P$ element copies (Ronsseray et al., 1989). Canonical $P$ elements have also colonized very recently the New World species $D$. willistoni, as suggested by an average pairwise difference between copies of less than 1\% (Silva, 2000) and by the low frequency of each insertion (A. Holyoke and M. Kidwell, unpublished results). In addition, these elements were shown to spread faster than neutral nuclear markers in natural populations, overcoming barriers such as moderate levels of population subdivision (Silva, 2000), and are now present in 5-14 copies per genome (A. Holyoke and M. Kidwell, unpublished results).

A more dramatic example of the potential for increase in copy number accompanying horizontal transfer was found for the mariner element in some host species. For example, the genome of the planarian, Dugesia tigrina, contains approximately 8000 copies of mariner and, of those sequenced, all are quite similar to each other (GarciaFernandez et al., 1995). Furthermore, the planarian mariners are characterized by full-length, uninterrupted reading frames and are dispersed throughout the genome. Together, these observations suggest recent transposition and spread following horizontal transfer.

\section{Factors Limiting the Spread of Transposable Elements}

The invasion of a new species after the initial integration into the host genome is not always quick, or even possible. Several factors might play a crucial role in TE spread, such as the effective population size of the host species (Charlesworth and Charlesworth, 1983; Brookfield and Badge, 1997; Quesneville and Anxolabéhère, 1997), selection (Nuzhdin, 1999, and references therein), repression of transposition, and the presence or absence of host factors required for transposition. The last two factors vary considerably between TE families and are discussed more extensively below.

\section{Host factors}

The effect of host factors on TE spread is well demonstrated by the difference in the taxonomic range of host species for the Pelement and mariner families. Although both these families are Class II TEs, Pelements are phylogenetically restricted to Diptera (mostly drosophilids), whereas mariner has been found in many animal phyla (Robertson et al., 2002). Despite their very similar structure and life cycle, these two families differ in a major aspect: the transposition of $P$ elements requires a host enzyme, IRBP (inverted repeat binding protein), which binds the element's inverted terminal repeats and is responsible for the element's initial excision from its chromosomal locus (Beall et al., 1994; Beall and Rio, 1997). In contrast, purified transposase alone is sufficient to support the mobility of mariner in vitro (Lampe et al., 1996). This striking distinction between these two Class II elements may alone explain the wide distribution of mariner in contrast to that of $P$. Indeed, if $P$ elements are transferred into the germ cells of a new host, their transposition and concomitant spread depend on the existence of a host protein with properties similar to those of IRBP. The failure of the canonical $P$ element to be mobilized in non-drosophilids following microinjection in the laboratory is possibly due to the lack of such factor (O'Brochta and Handler, 1988). Interestingly, Tc1 elements, which belong to Class II mariner-Tc1 superfamily and are widely distributed among animals and fungi (Plasterk, 1996), much like their mariner cousins require only transposase activity for their mobility (Vos et al., 1996). This apparent minimal requirement for mobility may explain why horizontal transfer between distantly related taxa is relatively common for $T c 1$ and mariner.

The influence of host factors on TE mobility was illustrated by comparing the dynamics of the spread of a TE family that was introduced into the genomes of two closely related species. When $P$ elements were introduced into laboratory populations of $D$. melanogaster and its sibling species $D$. simulans, there was a dramatic and repeatable difference in the population dynamics of $P$ element (Kimura and Kidwell, 1994; Higuet et al., 1996). $P$ elements are significantly more active in $D$. melanogaster, 
reaching a higher copy number per cell than in $D$. simulans. These results suggest that, in addition to the transposase, host-specific factors are necessary to support $P$ element mobility at a sufficient level to ensure its spread and subsequent persistence in a species, once it has been introduced by horizontal transfer. These host factors may be in the form of a facilitator of transposition, such as IRBP (Badge and Brookfield, 1997) or may be related to host systems not directly related to transposition, such as those related to DNA repair. Quesneville and Anxolabéhère (1997) have suggested that a species' ability to deal with the damage induced by $P$ element excision can determine the success or failure of horizontal transfer.

Regulation of copy number: repression of transposition vs. selection

Experimental data suggest that the initial stage of the invasion of a naive genome by $P$ elements is characterized by a very high transposition rate, on the order of $10^{-2}$ per element per generation (Engels, 1989, and references therein). That this may be the case for other TE families (even if not to the extreme seen in Pelements) is supported by the very high copy number attained by some TE families soon after invasion, as mentioned above for mariner in Dugesia. Eventually, however, copy number ceases to increase. This stabilization in copy number can be due either to selection at the host level or to a TE self-regulation mechanism (Charlesworth and Charlesworth, 1983). In the case of selection host fitness is a decreasing function of TE number. In the case of self-regulation, transposition rate is a decreasing function of TE number.

Regulation of transposition of Class I elements is still poorly understood. However, there is a growing body of evidence that suggests that self-regulation is not a significant force in the stabilization of copy number in these families, since there seems to be no negative correlation between transposition rate and copy number (Biémont et al., 1997; Vieira and Biémont, 1997; Pasyukova et al., 1998). Rather, selection has been suggested as the major force controlling Class I element copy number, especially because of the fitness costs associated with ectopic recombination (Charlesworth and Lapid, 1989; Maside et al., 2001). Repression of transposition of Class I elements can also be achieved by means of host-encoded peptides. This is the case for gypsy, the transposition of which is regulated by an X-linked gene called flamenco in $D$. melanogaster (Prud'homme et al., 1995). Varying rates of transposition of these elements among natural populations may be due to the presence of permissive and restrictive alleles, which are kept in balance by mutation and selection (Nuzhdin, 1999). This is probably a tight balance, delicately modulated by host -TE interactions and hence specific for each such pair, as suggested by the recent finding that flamenco cannot repress transposition of gypsy elements from other Drosophila species when these are introduced in D. melanogaster (Mejlumian et al., 2002). Finally, methylation of TE sequences can also play a role in repression of transposition in some organisms (Labrador and Corces, 1997; Matzke et al., 1999).

Self-regulation depends on repression of transposition, which encompasses many processes that reduce transposition rate to varying degrees. Self-regulation is known for Class II families. $P$ elements in particular have been intensively studied and several types of repressors have been defined. Type I repressors correspond to a truncated version of the $P$-encoded transposase, and are produced by alternative splicing of the element's mRNA; this yields a $66-\mathrm{kD}$ repressor protein that prevents $P$ element transcription (Misra and Rio, 1990; Gloor et al., 1993; Siebel et al., 1994; Roche et al., 1995). Transposition can also be repressed by a series of internally deleted $P$ elements, called type II repressors. These are usually byproducts of the repair of the double-stranded DNA break that occurs during $P$ element transposition. Supposedly, type II repressors act by binding the transposase itself (Rasmusson et al., 1993; Andrews and Gloor, 1995), by binding the element sequence and out-competing the transposase enzyme (Lee et al., 1996), and by antisense RNA interference (Simmons et al., 1996). The KPelement is the most abundant type II repressor in natural populations of $D$. melanogaster (Engels, 1989). Finally, the titration of transposase by its binding to defective or extrachromosomal $P$ element copies might also help reduce transposition rates (Simmons and Bucholz, 1985).

Repression of transposition in other Class II elements, even though not as well studied, seems to rely on selfregulation mechanisms as well (for reviews see Hartl et al., 1997; Labrador and Corces, 1997). These include alternative splicing of the elements's mRNA that can give rise to either repressor peptides or transposase (Mason et al., 1991), negative feedback dependent on the concentration of transposase (Lohe and Hartl, 1996; Labrador and Corces, 1997), transposase titration by methods such as dominant-negative complementation (Lohe et al., 1997), and/or RNA interference (Jensen et al., 1999). These studies support the contention that the mobility of Class II elements is, to a large extent, selfregulated.

\section{Correlates of Horizontal Transfer}

As described above, horizontal transfer is apparently more frequent among Class II than Class I TEs, and this pattern seems to be due in part to the different transposition mechanisms used by the two classes. Another reason for this difference may be that while Class II elements appear to be mostly self-regulating, Class I TEs are not. Could this difference in regulatory mechanism be related to the incidence of horizontal transfer? Possibly, if the degree to which self-regulation represses transposition is effective enough.

In order for a TE lineage to persist through time, the rate at which new functional elements arise must balance the rate at which they are lost (Charlesworth and Charlesworth, 1983). A functional element (those capable of transposition and which encode functional enzymes) is lost due to a variety of processes, which include random loss (e.g., failure of the host to reproduce), substitutions and insertions/deletions that render the transposase inactive, excision (e.g., a Class II element that, during transposition, fails to re-insert) and selection against individual hosts with specific deleterious insertions or with 
too many TE copies. When the rate of transposition is not high enough to counteract the effect of these processes, the TE lineage will eventually go extinct. Among Class I elements, the rate of transposition is apparently at least one order of magnitude larger that the rate of excision, and selection keeps TE copy number in check (Charlesworth and Langley, 1991).

A relevant question is whether the self-regulating Class II TEs can maintain a rate of transposition that is high enough to prevent lineage extinction, once repression is established. Not much is known about transposition rates of Class II TEs in natural population. However, laboratory studies show that a few generations after the introduction of $P$ elements into naive populations the $P$ cytotype becomes established, a condition characterized by the suppression of $P$ element transposition (Engels, 1979; Kidwell, 1985; Engels, 1989, and references therein). Although not thoroughly understood, the $P$ cytotype condition is maternally inherited and depends on both the presence and the location of $P$ element insertions, and is related to the transmission of repressor peptides or their mRNA to the zygote, through the oocyte's cytoplasm (see Labrador and Corces, 1997 for a review; Ronsseray et al., 1998; Ronsseray et al., 2001, Simmons et al., 2002). Truncated peptides with putative repressor capabilities have also been found in Drosophila species other than $D$. melanogaster, which shows that repressors can arise repeatedly (Nouaud and Anxolabéhère, 1997). Moreover, the presence of the $K P$ repressor at a high frequency in populations of $D$. melanogaster worldwide provide support for the idea that new repressors can quickly spread and be maintained by selection (Black et al., 1987; Jackson et al., 1988). These studies strongly suggest that repression of $P$ element transposition can be quite effective. Whether or not repression of transposition is as strong in other selfregulated Class II elements remains to be determined.

Finally it should be noted that complete repression of transposition may not be required for extinction of a TE lineage. Kaplan and collaborators (1985) have shown that self-regulating TE lineages are expected to go extinct when non-functional elements can be transposed by a transposase produced in trans, i.e., a transposase encoded by another element. This is the case for $P$ elements and, probably, for other Class II TE families as well.

Assuming, for the sake of argument, that self-regulation is indeed conducive to extinction, then continual horizontal transfer becomes necessary for the survival of Class II TE families. While Class I elements persist through an equilibrium between transposition and loss, Class II are always "on the run" (Figure 2). As long as repression persists, at least one TE copy must find its way into a naive genome, where repression is still absent, giving rise to a new pool of functional copies to re-initiate the cycle of transposition and spread. This scenario leads to a few quite interesting predictions. First, because it depends on how quickly repression of transposition arises, copy number per genome is likely to vary among populations and among species. There is already evidence that this is the case for $P$ elements, the copy number of which is known to differ among species of the willistonispecies group (Daniels and Strausbaugh, 1986). Second, in populations where the TE copy number is stable, an increase in the number of copies

Figure 2. Stages of the life cycle of a hypothetical Class II, self-regulated, transposable element lineage. (I) An element is transferred into a germline cell of host A. (ii) Once the element has successfully integrated into the host DNA and is expressed, transposition will start, with a concomitant rapid increase in copy number. (iii) Repression of transposition arises and spreads throughout the host population. As a result, the growth rate in copy number slows. (iv) At this time the rate of loss of functional elements is higher than the rate at which they are created by transposition, and the number of functional elements in the genome slowly decreases. This process that can take many millions of years (abbreviated period represented by a dashed line). ( $v$ ) Finally, no functional elements are left in the genome of host A, and this TE lineage becomes extinct. Sometime between (ii) and (v), a functional element may be transferred horizontally (HT) to a new host and the process begins anew. So, the death of the lineage in host A does not necessarily imply the death of the TE family. Eventually, another functional element may escape to yet another host. If, at this time, repression of transposition has subsided in host $A$, it can be invaded again. The presence of multiple, quite divergent TE subfamilies of mariner and $P$ elements in the same host is probably the signature of independent waves of horizontal transfer (Clark et al., 1995; Lampe et al., 2001). 
should be possible through the elimination of the source of repression. Finally, unless they are a recently formed family, self-regulated TEs should all show evidence of horizontal transfer. The maximum length of time before a horizontal transfer is required (time to extinction of the family) will depend on several characteristics, such as the number of copies per genome and the rate of loss of functional elements. In this context, the study of class II families in which transmission seems to be exclusively vertical, if any is found, would be extremely fruitful.

\section{Conclusions}

Successful TE horizontal transfer events depend on a stable transfer between donor and recipient and on the subsequent spread throughout the new host populations. Although detected for all types of TEs, horizontal transfer seems considerably more frequent among Class II than Class I families. Evidence summarized here indicates that this pattern is due to fundamental differences between the two TE Classes. The major transposition mechanism used by Class II elements is better suited for horizontal transfer than those used by Class I TE families. In addition, the type of copy number regulation used by Class II TEs, which seem to be mostly self-regulated, may make it impossible for these elements to sustain a rate of transposition that is compatible with their long-term survival within a single genome. Thus, horizontal transfer may be the chance event that dictates which Class II families survive and which do not.

Extensive genomic data, often in the form of complete genomes, is currently being gathered at an astonishing rate. Mining this type of data for TEs is sure to bring advances on many fronts. For example, it will make it possible to objectively assess the distribution of known TEs, to estimate more reliably the incidence of horizontal transfer among them, and to identify new TE families. Studies of horizontal transfer have practical implications as well. Some TEs, such as piggyBac and those of the mariner-Tc1 superfamily, are already being used as transformation vectors in a wide variety of taxa (Sherman et al., 1998; Rubin et al., 1999; Mamoun et al., 2000; Zhang et al., 2000; Handler, 2002). The usefulness of TEs in this context is phenomenal since, through insertional mutagenesis, they provide a tool to rapidly identify and recover of genes that contribute of specific phenotypes (Spradling et al., 1999; Fischer et al., 2001; Horn et al., 2003). In addition, the inherent ability of TEs to spread can be explored as a means to transform, and thus, ultimately, control, species that are involved in the transmission of diseases or that are, themselves, considered to be pests (Gueiros-Filho and Beverley, 1997; Atkinson et al., 2001).

The success of these elements as transformation vectors rests mainly on two bases: on studies of their transposition mechanisms that show transposase to be the only factor required for transposition. This suggests that the success of such experiments does not hinge on hostencoded factors, which might be absent in distantly related taxa. They also rely on studies of the occurrence of TEs that reveal the presence of specific elements across a wide variety of taxa, since this provides circumstantial evidence for the success of such elements as tools in transformation studies. Additional studies of horizontal transfer, by providing further insights into the features of interspecific transfer, may prove invaluable for the fields of functional and medical genomics.

\section{Acknowledgements}

We would like to thank Margaret G. Kidwell, David G. Harris and Shelby L. Bidwell for critical review of the manuscript, and for suggestions and lengthy discussions that significantly contributed to the clarity of the manuscript. We also thank Margaret G. Kidwell and Andrew J. Holyoake, and Jake Tu and Hongguang Shao for allowing us to use their unpublished results. J.C.S. was supported with funds from the National Institute of Allergy and Infectious Diseases, National Institutes of Health, award number U01 A1050913-02.

\section{References}

Andrews, J.D., and Gloor, G.B. 1995. A role for the KP leucine zipper in regulating $P$ element transposition in Drosophila melanogaster. Genetics 141: 587-594.

Anxolabéhère, D., Kidwell, M.G., and Periquet, G. 1988. Molecular characteristics of diverse populations are consistent with the hypothesis of a recent invasion of Drosophila melanogaster by mobile Pelements. Mol. Biol. Evol. 5: 252-269.

Arca, B., and Savakis, C. 2000. Distribution of the transposable element Minos in the genus Drosophila. Genetica 108: 263-267.

Atkinson, P.W., Pinkerton, A.C., and O'Brochta, D.A. 2001. Genetic transformation systems in insects. Annu. Rev. Entomol. 46: 317-346.

Auge-Gouillou, C., Bigot, Y., Pollet, N., Hamelin, M.H., Meunier-Rotival, M., and Periquet, G. 1995. Human and other mammalian genomes contain transposons of the mariner family. FEBS Lett. 368: 541-546.

Badge, R.M., and Brookfield, J.F. 1997. The role of host factors in the population dynamics of selfish transposable elements. J. Theor. Biol. 187: 261-271.

Beall, E.L., Admon, A., and Rio, D.C. 1994. A Drosophila protein homologous to the human p70 Ku autoimmune antigen interacts with the $P$ transposable element inverted repeats. Proc. Natl. Acad. Sci. USA. 91: 12681-12685.

Beall, E.L., and Rio, D.C. 1997. Drosophila P-element transposase is a novel site-specific endonuclease. Genes Dev. 11: 2137-2151.

Berg, D.E., and Howe, M.M., eds. 1989. Mobile DNA. American Society of Microbiology, Washington, D.C.

Biémont, C., Vieira, C., Borie, N., and Lepetit, D. 1999. Transposable elements and genome evolution: the case of Drosophila simulans. Genetica 107: 113-120.

Biémont, C., Vieira, C., Hoogland, C., Cizeron, G., Loevenbruck, C., Arnault, C., and Carante, J.P. 1997. Maintenance of transposable element copy number in natural populations of Drosophila melanogaster and $D$. simulans. Genetica 100: 161-166.

Black, D.M., Jackson, M.S., Kidwell, M.G., and Dover, G.A. 1987. KP elements repress $P$-induced hybrid dysgenesis 
in Drosophila melanogaster. EMBO J. 6: 4125-4135. Brookfield, J.F., and Badge, R.M. 1997. Population genetics models of transposable elements. Genetica 100: 281294.

Brunet, F., Godin, F., Bazin, C., and Capy, P. 1999. Phylogenetic analysis of Mos1-like transposable elements in the Drosophilidae. J. Mol. Evol. 49: 760-768.

Brunet, F., Godin, F., David, J.R., and Capy, P. 1994. The mariner transposable element in the Drosophilidae family. Heredity 73: 377-385.

Calvi, B.R., Hong, T.J., Findley, S.D., and Gelbart, W.M. 1991. Evidence for a common evolutionary origin of inverted repeat transposons in Drosophila and plants: hobo, Activator, and Tam3. Cell 66: 465-471.

Capy, P. 1998. Classification of transposable elements. In: Dynamics And Evolution Of Transposable Elements. P. Capy, C. Bazin, D. Higuet, and T. Langin, eds. Landes Bioscience, Austin. p. 37-52.

Capy, P., Anxolabéhère, D., and Langin, T. 1994. The strange phylogenies of transposable elements: are horizontal transfers the only explanation? Trends Genet. 10: 7-12.

Capy, P., Vitalis, R., Langin, T., Higuet, D., and Bazin, C. 1996. Relationships between transposable elements based upon the integrase-transposase domains: is there a common ancestor? J. Mol. Evol. 42: 359-368.

Charlesworth, B., and Charlesworth, D. 1983. The population dynamics of transposable elements. Genet. Res. 42: 1-27.

Charlesworth, B., and Langley, C.H. 1991. Population genetics of transposable elements in Drosophila. In: Evolution At The Molecular Level. R.K. Selander, A.G. Clark, and T.S. Whittam, eds. Sinauer Associates, Inc., Sunderland.

Charlesworth, B., and Lapid, A. 1989. A study of ten families of transposable elements on $\mathrm{X}$ chromosomes from a population of Drosophila melanogaster. Genet. Res. 54: 113-125.

Clark, J.B., Altheide, T.K., Schlosser, M.J., and Kidwell, M.G. 1995. Molecular evolution of $P$ transposable elements in the genus Drosophila. I. The saltans and willistoni species groups. Mol. Biol. Evol. 12: 902-913.

Clark, J.B., and Kidwell, M.G. 1997. A phylogenetic perspective on $P$ transposable element evolution in Drosophila. Proc. Natl. Acad. Sci. USA. 94: 11428-11433.

Clark, J.B., Kim, P.C., and Kidwell, M.G. 1998. Molecular evolution of $P$ transposable elements in the genus Drosophila. III. The melanogaster species group. Mol. Biol. Evol. 15: 746-755.

Clark, J.B., Maddison, W.P., and Kidwell, M.G. 1994. Phylogenetic analysis supports horizontal transfer of $P$ transposable elements. Mol. Biol. Evol. 11: 40-50.

Clark, J.B., Silva, J.C., and Kidwell, M.G. 2002. Evidence of horizontal transfer of $P$ transposable elements. In: Horizontal Gene Transfer. M. Syvanen, and C.I. Kado, eds. Academic Press, San Diego. p. 161-171.

Cummings, M.P. 1994. Transmission patterns of eukaryotic transposable elements: arguments for and against horizontal transfer. Trends Ecol. Evol. 9: 141-145.

Dai, L., and Zimmerly, S. 2002. Compilation and analysis of group II intron insertions in bacterial genomes: evidence for retroelement behavior. Nucleic Acids Res. 30: 10911102.

Daniels, S.B., Chovnick, A., and Boussy, I.A. 1990a. Distribution of the hobo transposable element in the genus Drosophila. Mol. Biol. Evol. 7: 589-606.

Daniels, S.B., Peterson, K.R., Strausbaugh, L.D., Kidwell, M.G., and Chovnick, A. 1990b. Evidence for horizontal transmission of the $P$ transposable element between Drosophila species. Genetics 124: 339-355.

Doolittle, W.F., and Sapienza, C. 1980. Selfish genes, the phenotype paradigm and genome evolution. Nature 284: 601-603.

Eickbush, D.G., and Eickbush, T.H. 1995. Vertical transmission of the retrotransposable elements $R 1$ and $R 2$ during the evolution of the Drosophila melanogaster species subgroup. Genetics 139: 671-684.

Engels, W. 1979. Hybrid dysgenesis in Drosophila melanogaster: rules of inheritance of female sterility. Genet. Res. 33: 219-236.

Engels, W. 1989. Pelements in Drosophila melanogaster. In: Mobile DNA. D.E. Berg, and M.M. Howe, eds. American Society of Microbiology, Washington, D.C. p. 437-483.

Engels, W.R. 1992. The origin of Pelements in Drosophila melanogaster. Bioessays 14: 681-686.

Finnegan, D. 1992. Transposable elements. In: The Genome of Drosophila melanogaster. D.L. Lindsley, and G. Zimm, eds. Academic Press, New York. p. 1092-1107.

Finnegan, D.J. 1989. Eukaryotic transposable elements and genome evolution. Trends Genet. 5: 103-107.

Fischer, S.E., Wienholds, E., and Plasterk, R.H. 2001. Regulated transposition of a fish transposon in the mouse germ line. Proc. Natl. Acad. Sci. USA. 98: 6759-6764.

Fraser, M.J., Brusca, J.S., Smith, G.E., and Summers, M.D. 1985. Transposon-mediated mutagenesis of a baculovirus. Virology 145: 356-361.

Frissen, N., Brandes, A., and Helsop-Harrison, J.S. 2001. Diversity, origin, and distribution of retrotranspososns (gypsy and copia) in conifers. Mol. Biol. Evol. 18: 11761188.

Garcia-Fernandez, J., Bayascas-Ramirez, J.R., Marfany, G., Munoz-Marmol, A.M., Casali, A., Baguna, J., and Salo, E. 1995. High copy number of highly similar mariner-like transposons in planarian (Platyhelminthe): evidence for a trans-phyla horizontal transfer. Mol. Biol. Evol. 12: 421431.

Gloor, G.B., Preston, C.R., Johnson-Schlitz, D.M., Nassif, N.A., Phillis, R.W., Benz, W.K., Robertson, H.M., and Engels, W.R. 1993. Type I repressors of $P$ element mobility. Genetics 135: 81-95.

Gomulski, L.M., Torti, C., Bonizzoni, M., Moralli, D., Raimondi, E., Capy, P., Gasperi, G., and Malacrida, A.R. 2001. A new basal subfamily of mariner elements in Ceratitis rosa and other tephritid flies. J. Mol. Evol. 53: 597-606.

Gonzalez, P., and Lessios, H.A. 1999. Evolution of sea urchin retroviral-like (SURL) elements: evidence from 40 echinoid species. Mol. Biol. Evol. 16: 938-952.

Good, A.G., Meister, G.A., Brock, H.W., Grigliatti, T.A., and Hickey, D.A. 1989. Rapid spread of transposable $P$ 
elements in experimental populations of Drosophila melanogaster. Genetics 122: 387-396.

Gueiros-Filho, F.J., and Beverley, S.M. 1997. Transkingdom transposition of the Drosophila element mariner within the protozoan Leishmania. Science 276: 17161719.

Hagemann, S., Haring, E., and Pinsker, W. 1996. Repeated horizontal transfer of $P$ transposons between Scaptomyza pallida and Drosophila bifasciata. Genetica 98: 43-51.

Hagemann, S., Miller, W.J., and Pinsker, W. 1992. Identification of a complete $P$-elements in the genome of Drosophila bifasciata. Nucleic Acids Res. 20: 409-413.

Hagemann, S., Miller, W.J., and Pinsker, W. 1994. Two distinct $P$ element subfamilies in the genome of Drosophila bifasciata. Mol. Gen. Genet. 244: 168-175.

Hamada, M., Kido, Y., Himberg, M., Reist, J.D., Ying, C., Hasegawa, M., and Okada, N. 1997. A newly isolated family of short interspersed repetitive elements (SINEs) in coregonid fishes (whitefish) with sequences that are almost identical to those of the Smal family of repeats: possible evidence for the horizontal transfer of SINEs. Genetics 146: 355-367.

Handler, A. 2002. Use of the piggyBac transposon for germline transformation of insects. Insect Biochem. Mol. Biol. 32: 1211 .

Haring, E., Hagemann, S., and Pinsker, W. 2000. Ancient and recent horizontal invasions of drosophilids by $P$ elements. J. Mol. Evol. 51: 577-586.

Hartl, D.L., Lohe, A.R., and Lozovskaya, E.R. 1997. Modern thoughts on an ancyent marinere: function, evolution, regulation. Annu. Rev. Genet. 31: 337-358.

Heath, B.D., Butcher, R.D., Whitfield, W.G., and Hubbard, S.F. 1999. Horizontal transfer of Wolbachia between phylogenetically distant insect species by a naturally occurring mechanism. Curr. Biol. 9: 313-316.

Herédia, F. 2002 Evolução do retroelemento gypsy em espécies de Drosophila e Zaprionis indianus. Uma abordagem filogenética, Doctoral Thesis, Universidade Federal do Rio Grande do Sul, Porto Alegre, Brazil.

Hickey, D.A. 1982. Selfish DNA: a sexually-transmitted nuclear parasite. Genetics 101: 519-531.

Higuet, D., Merçot, H., Allouis, S., and Montchamp-Moreau, C. 1996. The relationship between structural variation and dysgenic properties of $P$ elements in long-established $\mathrm{P}$ transformed lines of Drosophila simulans. Heredity 77 : 9-15.

Horn, C., Offen, N., Nystedt, S., Hacker, U., and Wimmer, E.A. 2003. piggyBac-based insertional mutagenesis and enhancer detection as a tool for functional insect genomics. Genetics 163: 647-661.

Houck, M.A., Clark, J.B., Peterson, K.R., and Kidwell, M.G. 1991. Possible horizontal transfer of Drosophila genes by the mite Proctolaelaps regalis. Science 253: 11251128.

Ivics, Z., Hackett, P.B., Plasterk, R.H., and Izsvák, Z. 1997. Molecular reconstruction of Sleeping Beauty, a Tc1-like transposon from fish, and its transposition in human cells. Cell 91: 501-510.

Ivics, Z., Izsvák, Z., Minter, A., and Hackett, P.B. 1996. Indentification of functional domains and evolution of TC1like transposable elements. Proc. Natl. Acad. Sci. USA.
93: 5008-5013.

Jackson, M.S., Black, D.M., and Dover, G.A. 1988. Amplification of KP elements associated with the repression of hybrid dysgenesis in Drosophila melanogaster. Genetics 120: 1003-1013.

Jarvik, T., and Lark, K.G. 1998. Characterization of Soymar1, a mariner element in soybean. Genetics 149: 1569-1574.

Jehle, J.A., Fritsch, E., Nickel, A., Huber, J., and Backhaus, H. 1995. TCl4.7: a novel lepidopteran transposon found in Cydia pomonella granulosis virus. Virology 207: 369379.

Jensen, S., Gassama, M.P., and Heidmann, T. 1999. Taming of transposable elements by homologydependent gene silencing. Nat. Genet. 21: 209-212.

Jordan, I.K., Matyunina, L.V., and McDonald, J.F. 1999. Evidence for the recent horizontal transfer of long terminal repeat retrotransposon. Proc. Natl. Acad. Sci. USA. 96: 12621-12625.

Jordan, I.K., Rogozin, I.B., Glazko, G.V., and Koonin, E.V. 2003. Origin of a substantial fraction of human regulatory sequences from transposable elements. Trends Genet. 19: 68-72.

Kapitonov, V.V., and Jurka, J. 2001. Rolling-circle transposons in eukaryotes. Proc. Natl. Acad. Sci. USA. 98: 8714-8719.

Kaplan, N., Darden, T., and Langley, C. 1985. Evolution and extinction of transposable elements in Mendelian populations. Genetics 109: 459-480.

Kaufman, P.D., and Rio, D.C. 1992. Pelement transposition in vitro proceeds by a cut-and-paste mechanism and uses GTP as a cofactor. Cell 69: 27-39.

Kidwell, M.G. 1983. Evolution of hybrid dysgenesis determinants in Drosophila melanogaster. Proc. Natl. Acad. Sci. USA. 80: 1655-1659.

Kidwell, M.G. 1985. Hybrid dysgenesis in Drosophila melanogaster: nature and inheritance of $P$ element regulation. Genetics 111: 337-350.

Kidwell, M.G. 1992. Horizontal transfer of $P$ elements and other short inverted repeat transposons. Genetica 86: 275-286.

Kidwell, M.G. 1993. Lateral transfer in natural populations of eukaryotes. Annu. Rev. Genet. 27: 235-256.

Kidwell, M.G. 1994. The evolutionary history of the $P$ family of transposable elements. J. Hered. 85: 339-346.

Kidwell, M.G., Kidwell, J.F., and Sved, J.A. 1977. Hybrid dysgenesis in Drosophila melanogaster: a syndrome of aberrant traits including mutation, sterility and male recombination. Genetics 36: 813-833.

Kidwell, M.G., Kimura, K., and Black, D.M. 1988. Evolution of hybrid dysgenesis potential following $P$ element contamination in Drosophila melanogaster. Genetics 119: 815-828.

Kidwell, M.G., and Lisch, D. 2000. Transposable elements and host genome evolution. Trends Ecol. Evol. 15: 9599.

Kim, A., Terzian, C., Santamaria, P., Pélisson, A., Prud'homme, N., and Bucheton, A. 1994. Retroviruses in invertebrates: the gypsy retrotransposon is apparently an infectious retrovirus of Drosophila melanogaster. Proc. Natl. Acad. Sci. USA. 91: 1285-1289. 
Kimura, K., and Kidwell, M.G. 1994. Differences in $P$ element population dynamics between the sibling species Drosophila melanogaster and Drosophila simulans. Genet. Res. 63: 27-38.

Kimura, M. 1980. A simple method for estimating evolutionary rate of base substitutions through comparative studies of nucleotide sequences. J. Mol. Evol. 16: 111-120.

Koga, A., Shimada, A., Shima, A., Sakaizumi, M., Tachida, H., and Hori, H. 2000. Evidence for recent invasion of the medaka fish genome by the Tol2 transposable element. Genetics 155: 273-281.

Kondo, N., Nikoh, N., ljichi, N., Shimada, M., and Fukatsu, T. 2002. Genome fragment of Wolbachia endosymbiont transferred to $X$ chromosome of host insect. Proc. Natl. Acad. Sci. USA. 99: 14280-14285.

Konieczny, A., Voytas, D.F., Cummings, M.P., and Ausubel, F.M. 1991. A superfamily of Arabidopsis thaliana retrotransposons. Genetics 127: 801-809.

Kordis, D., and Gubensek, F. 1995. Horizontal SINE transfer between vertebrate classes. Nat. Genet. 10: 131132.

Labrador, M., and Corces, V.G. 1997. Transposable element-host interactions: regulation of insertion and excision. Annu. Rev. Genet. 31: 381-404.

Lam, W.L., Seo, P., Robison, K., Virk, S., and Gilbert, W. 1996. Discovery of amphibian Tc1-like transposon families. J. Mol. Biol. 257:359-366.

Lambert, M.E., McDonald, J.F., and Weinstein, I.B., eds. 1988. Eukaryotic Transposable Elements as Mutagenic Agents. Cold Spring Harbor Laboratory Press.

Lampe, D.J., Churchill, M.E., and Robertson, H.M. 1996. A purified mariner transposase is sufficient to mediate transposition in vitro. EMBO J. 15: 5470-5479.

Lampe, D.J., Walden, K.K., and Robertson, H.M. 2001. Loss of transposase-DNA interaction may underlie the divergence of mariner family transposable elements and the ability of more than one mariner to occupy the same genome. Mol. Biol. Evol. 18: 954-961.

Langin, T., Capy, P., and Daboussi, M.J. 1995. The transposable element impala, a fungal member of the Tc1-mariner superfamily. Mol. Gen. Genet. 246: 19-28.

Lécher, P., Bucheton, A., and Pélisson, A. 1997. Expression of the Drosophila retrovirus gypsy as ultrastructurally detectable particles in the ovaries of flies carrying a permissive flamenco allele. J. Gen. Virol. 78: 2379-2388.

Lee, C.C., Mul, Y.M., and Rio, D.C. 1996. The Drosophila $P$-element KP repressor protein dimerizes and interacts with multiple sites on P-element DNA. Mol. Cell. Biol. 16: 5616-5622.

Lerat, E., Brunet, F., Bazin, C., and Capy, P. 1999. Is the evolution of transposable elements modular? Genetica 107: 15-25.

Lidholm, D.A., Gudmundsson, G.H., and Boman, H.G. 1991. A highly repetitive, mariner-like element in the genome of Hyalophora cecropia. J. Biol. Chem. 266: 11518-11521.

Lohe, A.R., De Aguiar, D., and Hartl, D.L. 1997. Mutations in the mariner transposase: the $D, D(35) E$ consensus sequence is nonfunctional. Proc. Natl. Acad. Sci. USA. 94: 1293-1297.
Lohe, A.R., and Hartl, D.L. 1996. Autoregulation of mariner transposase activity by overproduction and dominantnegative complementation. Mol. Biol. Evol. 13: 549-555.

Lohe, A.R., Moriyama, E.N., Lidholm, D.A., and Hartl, D.L. 1995. Horizontal transmission, vertical inactivation, and stochastic loss of mariner-like transposable elements. Mol. Biol. Evol. 12: 62-72.

Loreto, E.L., Valente, V.L., Zaha, A., Silva, J.C., and Kidwell, M.G. 2001. Drosophila mediopunctata Pelements: a new example of horizontal transfer. J. Hered. 92: 375-381.

Luan, D.D., Korman, M.H., Jakubczak, J.L., and Eickbush, T.H. 1993. Reverse transcription of R2Bm RNA is primed by a nick at the chromosomal target site: a mechanism for non-LTR retrotransposition. Cell 72: 595-605.

Mackay, T.F. 1989. Transposable elements and fitness in Drosophila melanogaster. Genome 31: 284-295.

Makalowski, W. 2000. Genomic scrap yard: how genomes utilize all that junk. Gene 259: 61-67.

Malik, H.S., Burke, W.D., and Eickbush, T.H. 1999. The age and evolution of non-LTR retrotransposable elements. Mol. Biol. Evol. 16: 793-805.

Malik, H.S., and Eickbush, T.H. 2001. Phylogenetic analysis of ribonuclease $\mathrm{H}$ domains suggests a late, chimeric origin of LTR retrotransposable elements and retroviruses. Genome Res. 11: 1187-1197.

Mamoun, C.B., Gluzman, I.Y., Beverley, S.M., and Goldberg, D.E. 2000. Transposition of the Drosophila element mariner within the human malaria parasite Plasmodium falciparum. Mol. Biochem. Parasitol. 110: 405-407.

Maruyama, K., and Hartl, D.L. 1991. Evidence for interspecific transfer of the transposable element mariner between Drosophila and Zaprionus. J. Mol. Evol. 33: 514524.

Maside, X., Bartolome, C., Assimacopoulos, S., and Charlesworth, B. 2001. Rates of movement and distribution of transposable elements in Drosophila melanogaster: in situ hybridization vs Southern blotting data. Genet. Res. 78: 121-136.

Mason, P., Strem, M., and Fedoroff, N. 1991. The tnpA and tnpD gene products of the Spm element are required for transposition in tobacco. Plant Cell 3: 73-85.

Matzke, M., Mette, M., Aufsatz, W., Jakowitsch, J., and Matzke, A. 1999. Host defenses to parasitic sequences and the evolution of epigenetic control mechanisms. Genetica 107: 271-287.

McDonald, J.F. 1993. Evolution and consequences of transposable elements. Curr. Opin. Genet. Dev. 3: 855864.

McFadden, J., and Knowles, G. 1997. Escape from evolutionary stasis by transposon-mediated deleterious mutations. J. Theor. Biol. 186: 441-447.

Mejlumian, L., Pélisson, A., Bucheton, A., and Terzian, C. 2002. Comparative and functional studies of Drosophila species invasion by the gypsy endogenous retrovirus. Genetics 160: 201-209.

Mendiola, M.V., Bernales, I., and de la Cruz, F. 1994. Differential roles of the transposon termini in IS91 transposition. Proc. Natl. Acad. Sci. USA. 91: 1922-1926. Miller, D.W., and Miller, L.K. 1982. A virus mutant with an insertion of a copia-like transposable element. Nature 299: 562-564. 
Misra, S., and Rio, D.C. 1990. Cytotype control of Drosophila $P$ element transposition: the $66 \mathrm{kd}$ protein is a repressor of transposase activity. Cell 62: 269-284.

Mizrokhi, L.J., and Mazo, A.M. 1990. Evidence for horizontal transmission of the mobile element jockey between distant Drosophila species. Proc. Natl. Acad. Sci. USA. 87: 9216-9220.

Nekrutenko, A., and Li, W.H. 2001. Transposable elements are found in a large number of human protein-coding genes. Trends Genet. 17: 619-621.

Nouaud, D., and Anxolabéhère, D. 1997. P element domestication: a stationary truncated $P$ element may encode a 66-kDa repressor-like protein in the Drosophila montium species subgroup. Mol. Biol. Evol. 14: 11321144.

Nuzhdin, S.V. 1999. Sure facts, speculations, and open questions about the evolution of transposable element copy number. Genetica 107: 129-137.

O'Brochta, D.A., and Handler, A.M. 1988. Mobility of $P$ elements in drosophilids and nondrosophilids. Proc. Natl. Acad. Sci. USA. 85: 6052-6056.

Oosumi, T., Belknap, W.R., and Garlick, B. 1995. Mariner transposons in humans. Nature 378: 672.

Orgel, L.E., and Crick, F.H. 1980. Selfish DNA: the ultimate parasite. Nature 284: 604-607.

Pasyukova, E.G., Nuzhdin, S.V., and Filatov, D.A. 1998. The relationship between the rate of transposition and transposable element copy number for copia and Doc retrotransposons of Drosophila melanogaster. Genet. Res. 72: 1-11.

Pélisson, A., Teysset, L., Chalvet, F., Kim, A., Prud'homme, N., Terzian, C., and Bucheton, A. 1997. About the origin of retroviruses and the co-evolution of the gypsy retrovirus with the Drosophila flamenco host gene. Genetica 100: 29-37.

Pinsker, W., Haring, E., Hagemann, S., and Miller, W.J. 2001. The evolutionary life history of $P$ transposons: from horizontal invaders to domesticated neogenes. Chromosoma 110: 148-158.

Plasterk, R.H. 1996. The Tc1/mariner transposon family. Curr Top Microbiol. Immunol. 204: 125-143.

Prud'homme, N., Gans, M., Masson, M., Terzian, C., and Bucheton, A. 1995. Flamenco, a gene controlling the gypsy retrovirus of Drosophila melanogaster. Genetics 139: 697-711.

Quesneville, H., and Anxolabéhère, D. 1997. A simulation of $P$ element horizontal transfer in Drosophila. Genetica 100: 295-307.

Rasmusson, K.E., Raymond, J.D., and Simmons, M.J. 1993. Repression of hybrid dysgenesis in Drosophila melanogaster by individual naturally occurring $P$ elements. Genetics 133: 605-622.

Remsen, J., and O'Grady, P. 2002. Phylogeny of Drosophilinae (Diptera: Drosophilidae), with comments on combined analysis and character support. Mol. Phylogenet. Evol. 24: 249-264.

Robertson, H.M. 1997. Multiple mariner transposons in flatworms and hydras are related to those of insects. J. Hered. 88: 195-201.

Robertson, H.M., and Lampe, D.J. 1995. Recent horizontal transfer of a mariner transposable element among and between Diptera and Neuroptera. Mol. Biol. Evol. 12: 850862.

Robertson, H.M., and MacLeod, E.G. 1993. Five major subfamilies of mariner transposable elements in insects, including the Mediterranean fruit fly, and related arthropods. Insect. Mol. Biol. 2: 125-139.

Robertson, H.M., Soto-Adames, F.N., Walden, K.K., Avancini, R.M., and Lampe, D.J. 2002. The mariner transposons of animals: horizontally jumping genes. In: Horizontal Gene Transfer. M. Syvanen, and C.I. Kado, eds. Academic Press, San Diego, CA.

Roche, S.E., Schiff, M., and Rio, D.C. 1995. P-element repressor autoregulation involves germ-line transcriptional repression and reduction of third intron splicing. Genes Dev. 9: 1278-1288.

Ronsseray, S., Boivin, A., and Anxolabéhère, D. 2001. $P$ Element repression in Drosophila melanogaster by variegating clusters of $\mathrm{P}$-lacZ-white transgenes. Genetics 159: 1631-1642.

Ronsseray, S., Lehmann, M., and Anxolabéhère, D. 1989. Copy number and distribution of $P$ and $/$ mobile elements in Drosophila melanogaster populations. Chromosoma 98: 207-214.

Ronsseray, S., Marin, L., Lehmann, M., and Anxolabéhère, D. 1998. Repression of hybrid dysgenesis in Drosophila melanogaster by combinations of telomeric $P$-element reporters and naturally occurring $P$ elements. Genetics 149: 1857-1866.

Rubin, E.J., Akerley, B.J., Novik, V.N., Lampe, D.J., Husson, R.N., and Mekalanos, J.J. 1999. In vivo transposition of mariner-based elements in enteric bacteria and mycobacteria. Proc. Natl. Acad. Sci. USA. 96: 1645-1650.

Rubin, G.M., and Spradling, A.C. 1982. Genetic transformation of Drosophila with transposable element vectors. Science 218: 348-353.

Shao, H. and Tu, Z. 2001. Expanding the diversity of the IS630-Tc1-mariner superfamily: discovery of a unique DD37E transposon and reclassification of the DD37D and DD39D transposons. Genetics 159: 1103-1115.

Sherman, A., Dawson, A., Mather, C., Gilhooley, H., Li, Y., Mitchell, R., Finnegan, D., and Sang, H. 1998. Transposition of the Drosophila element mariner into the chicken germ line. Nat. Biotechnol. 16: 1050-1053.

Siebel, C.W., Kanaar, R., and Rio, D.C. 1994. Regulation of tissue-specific $P$-element pre-mRNA splicing requires the RNA-binding protein PSI. Genes Dev. 8: 1713-1725.

Silva, J.C. 2000 Population genetics of $P$ transposable elements and their host species, with emphasis on Drosophila willistoni and Drosophila sturtevanti, Doctoral Thesis, The University of Arizona, Tucson.

Silva, J.C., and Kidwell, M.G. 2000. Horizontal transfer and selection in the evolution of $P$ elements. Mol. Biol. Evol. 17: $1542-1557$.

Silva, J.C., Shabalina, S.A., Harris, D.G., Spouge, J.L., and Kondrashov, A.S. 2003. Conserved fragments of transposable elements in intergenic regions: evidence for widespread recruitment of MIR- and L2-derived sequences within the mouse and human genomes. Genet. Res. 82: 1-18.

Simmons, G.M. 1992. Horizontal transfer of hobo transposable elements within the Drosophila 
melanogaster species complex: evidence from DNA sequencing. Mol. Biol. Evol. 9: 1050-1060.

Simmons, M.J., and Bucholz, L.M. 1985. Transposase titration in Drosophila melanogaster: a model of cytotype in the P-M system of hybrid dysgenesis. Proc. Natl. Acad. Sci. USA. 82: 8119-8123.

Simmons, M.J., Haley, K.J., and Thompson, S.J. 2002. Maternal transmission of $P$ element transposase activity in Drosophila melanogaster depends on the last $P$ intron. Proc. Natl. Acad. Sci. USA. 99: 9306-9309.

Simmons, M.J., Raymond, J.D., Grimes, C.D., Belinco, C., Haake, B.C., Jordan, M., Lund, C., Ojala, T.A., and Papermaster, D. 1996. Repression of hybrid dysgenesis in Drosophila melanogaster by heat-shock-inducible sense and antisense $P$-element constructs. Genetics 144: 1529-1544.

Simonelig, M., and Anxolabéhère, D. 1991. A Pelement of Scaptomyza pallida is active in Drosophila melanogaster. Proc. Natl. Acad. Sci. USA. 88: 6102-6106.

Smit, A.F., and Riggs, A.D. 1996. Tiggers and DNA transposon fossils in the human genome. Proc. Natl. Acad. Sci. USA. 93: 1443-1448.

Spradling, A.C., Stern, D., Beaton, A., Rhem, E.J., Laverty, T., Mozden, N., Misra, S., and Rubin, G.M. 1999. The Berkeley Drosophila Genome Project gene disruption project: Single $P$-element insertions mutating $25 \%$ of vital Drosophila genes. Genetics 153: 135-177.

Stuart-Rogers, C., and Flavell, A.J. 2001. The evolution of Ty1-copia group retrotransposons in gymnosperms. Mol. Biol. Evol. 18: 155-163.

Terzian, C., Ferraz, C., Demaille, J., and Bucheton, A. 2000. Evolution of the Gypsy endogenous retrovirus in the Drosophila melanogaster subgroup. Mol. Biol. Evol. 17: 908-914.

Vazquez-Manrique, R.P., Hernandez, M., MartínezSebastián, M.J., and de Frutos, R. 2000. Evolution of gypsy endogenous retrovirus in the Drosophila obscura species group. Mol. Biol. Evol. 17: 1185-1193.

Vieira, C., and Biémont, C. 1997. Transposition rate of the
412 retrotransposable element is independent of copy number in natural populations of Drosophila simulans. Mol. Biol. Evol. 14: 185-188.

Vieira, C., Lepetit, D., Dumont, S., and Biémont, C. 1999. Wake up of transposable elements following Drosophila simulans worldwide colonization. Mol. Biol. Evol. 16: 1251-1255.

Vilela, C.C. 1999. Is Zaprionus indianus Gupta, 1970 (Diptera, Drosophilidea) currently colonizing the Neotropical region? Drosophila Information Service 82: 37-39.

Volff, J.N., Korting, C., and Schartl, M. 2000. Multiple lineages of the non-LTR retrotransposon Rex1 with varying success in invading fish genomes. Mol Biol Evol 17: 1673-1684.

Vos, J.C., De Baere, I., and Plasterk, R.H. 1996. Transposase is the only nematode protein required for in vitro transposition of Tc1. Genes Dev. 10: 755-761.

Xiong, Y., and Eickbush, T.H. 1990. Origin and evolution of retroelements based upon their reverse transcriptase sequences. EMBO J. 9: 3353-3362.

Yoshiyama, M., Tu, Z., Kainoh, Y., Honda, H., Shono, T., and Kimura, K. 2001. Possible horizontal transfer of a transposable element from host to parasitoid. Mol. Biol. Evol. 18: 1952-1958.

Zhang, J.K., Pritchett, M.A., Lampe, D.J., Robertson, H.M., and Metcalf, W.W. 2000. In vivo transposon mutagenesis of the methanogenic archaeon Methanosarcina acetivorans C2A using a modified version of the insect mariner-family transposable element Himar1. Proc. Natl. Acad. Sci. USA. 97: 9665-9670.

Zimmerly, S., Guo, H., Perlman, P.S., and Lambowitz, A.M. 1995. Group II intron mobility occurs by target DNAprimed reverse transcription. Cell 82: 545-554.

Zupunski, V., Gubensek, F., and Kordis, D. 2001. Evolutionary dynamics and evolutionary history in the RTE clade of non-LTR retrotransposons. Mol. Biol. Evol. 18: 1849-1863. 


\section{Further Reading}

Caister Academic Press is a leading academic publisher of advanced texts in microbiology, molecular biology and medical research. Full details of all our publications at caister.com

- MALDI-TOF Mass Spectrometry in Microbiology Edited by: M Kostrzewa, S Schubert (2016) www.caister.com/malditof

- Aspergillus and Penicillium in the Post-genomic Era Edited by: RP Vries, IB Gelber, MR Andersen (2016) www.caister.com/aspergillus2

- The Bacteriocins: Current Knowledge and Future Prospects Edited by: RL Dorit, SM Roy, MA Riley (2016)

www.caister.com/bacteriocins

- Omics in Plant Disease Resistance Edited by: V Bhadauria (2016) www.caister.com/opd

- Acidophiles: Life in Extremely Acidic Environments Edited by: R Quatrini, DB Johnson (2016) www.caister.com/acidophiles

- Climate Change and Microbial Ecology: Current Research and Future Trend

Edited by: J Marxsen (2016)

www.caister.com/climate

- Biofilms in Bioremediation: Current Research and Emerging Technologies

Edited by: G Lear (2016)

www.caister.com/biorem

- Microalgae: Current Research and Applications Edited by: MN Tsaloglou (2016) www.caister.com/microalgae

- Gas Plasma Sterilization in Microbiology: Theory, Applications, Pitfalls and New Perspectives Edited by: H Shintani, A Sakudo (2016) www.caister.com/gasplasma

- Virus Evolution: Current Research and Future Directions Edited by: SC Weaver, M Denison, M Roossinck, et al. (2016) www.caister.com/virusevol

- Arboviruses: Molecular Biology, Evolution and Control Edited by: N Vasilakis, DJ Gubler (2016) www.caister.com/arbo

- Shigella: Molecular and Cellular Biology Edited by: WD Picking, WL Picking (2016) www.caister.com/shigella

-Aquatic Biofilms: Ecology, Water Quality and Wastewater Treatment

Edited by: AM Romaní, H Guasch, MD Balaguer (2016)

www.caister.com/aquaticbiofilms

- Alphaviruses: Current Biology

Edited by: S Mahalingam, L Herrero, B Herring (2016)

www.caister.com/alpha

- Thermophilic Microorganisms

Edited by: F Li (2015)

www.caister.com/thermophile
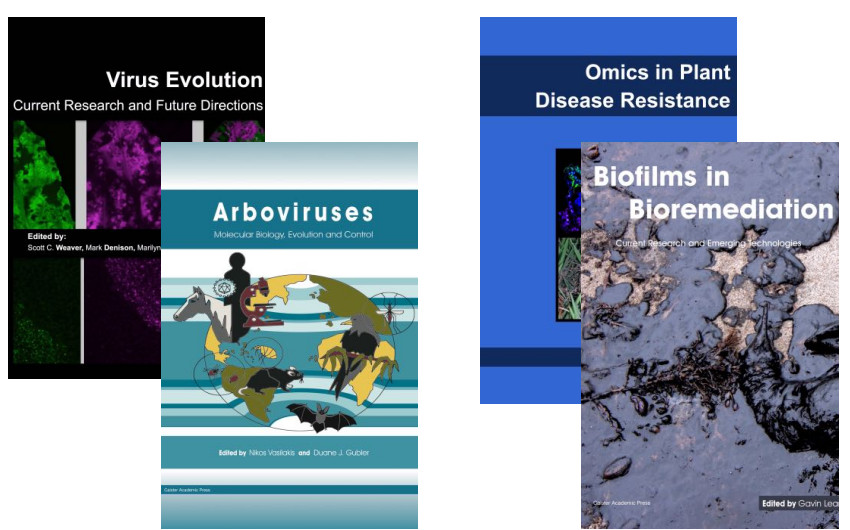
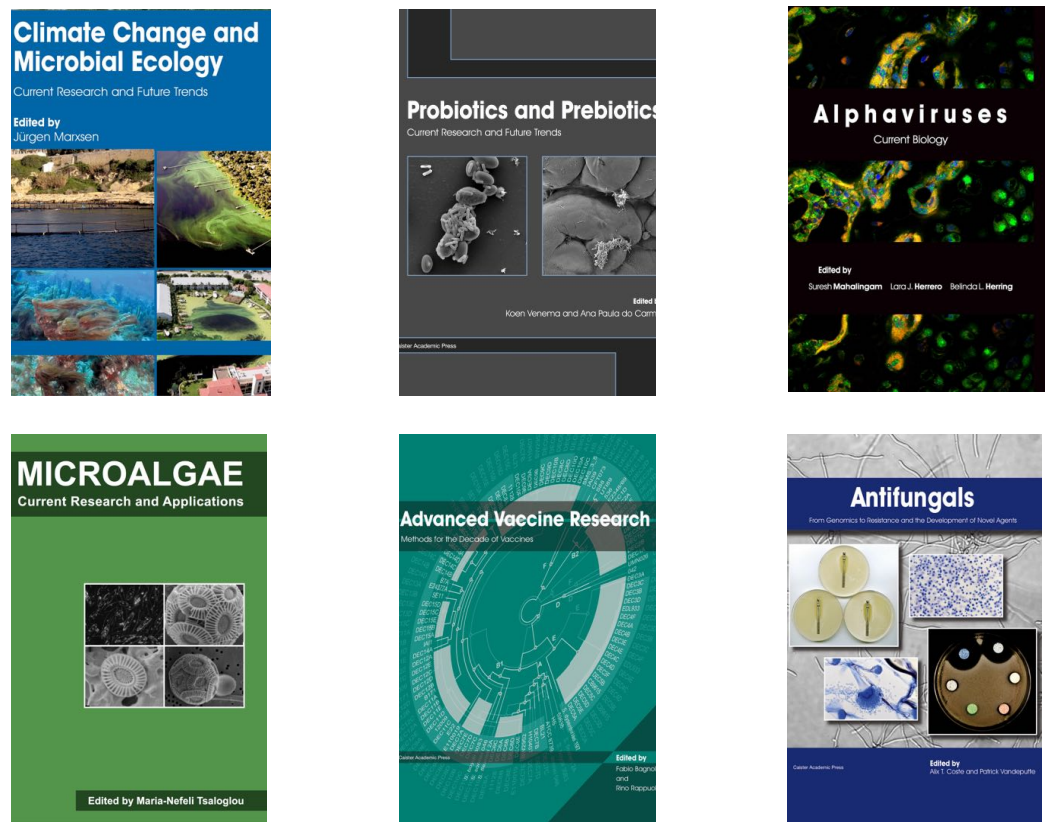

- Flow Cytometry in Microbiology: Technology and Applications Edited by: MG Wilkinson (2015) www.caister.com/flow

- Probiotics and Prebiotics: Current Research and Future Trends Edited by: K Venema, AP Carmo (2015) www.caister.com/probiotics

- Epigenetics: Current Research and Emerging Trends Edited by: BP Chadwick (2015) www.caister.com/epigenetics2015

- Corynebacterium glutamicum: From Systems Biology to Biotechnological Applications

Edited by: A Burkovski (2015)

www.caister.com/cory2

- Advanced Vaccine Research Methods for the Decade of Vaccines

Edited by: F Bagnoli, R Rappuoli (2015)

www.caister.com/vaccines

- Antifungals: From Genomics to Resistance and the Development of Novel Agents

Edited by: AT Coste, P Vandeputte (2015)

www.caister.com/antifungals

- Bacteria-Plant Interactions: Advanced Research and Future Trends Edited by: J Murillo, BA Vinatzer, RW Jackson, et al. (2015) www.caister.com/bacteria-plant

\section{- Aeromonas}

Edited by: J Graf (2015)

www.caister.com/aeromonas

- Antibiotics: Current Innovations and Future Trends

Edited by: S Sánchez, AL Demain (2015)

www.caister.com/antibiotics

- Leishmania: Current Biology and Contro Edited by: S Adak, R Datta (2015) www.caister.com/leish2

- Acanthamoeba: Biology and Pathogenesis (2nd edition) Author: NA Khan (2015)

www.caister.com/acanthamoeba2

- Microarrays: Current Technology, Innovations and Applications Edited by: Z He (2014)

www.caister.com/microarrays2

- Metagenomics of the Microbial Nitrogen Cycle: Theory, Methods and Applications

Edited by: D Marco (2014)

www.caister.com/n2 